University of Nebraska - Lincoln

DigitalCommons@University of Nebraska - Lincoln

School-Based Extracurricular Activity Involvement and Adolescent Self-Esteem: A Growth-Curve Analysis

Lisa A. Kort-Butler

University of Nebraska-Lincoln, lkortbutler2@unl.edu

Kellie J. Hagewen

University of Nebraska-Lincoln, kellie.hagewen@csn.edu

Follow this and additional works at: https://digitalcommons.unl.edu/sociologyfacpub

Part of the Developmental Psychology Commons, and the Other Sociology Commons

Kort-Butler, Lisa A. and Hagewen, Kellie J., "School-Based Extracurricular Activity Involvement and Adolescent Self-Esteem: A Growth-Curve Analysis" (2011). Sociology Department, Faculty Publications. 189.

https://digitalcommons.unl.edu/sociologyfacpub/189

This Article is brought to you for free and open access by the Sociology, Department of at DigitalCommons@University of Nebraska - Lincoln. It has been accepted for inclusion in Sociology Department, Faculty Publications by an authorized administrator of DigitalCommons@University of Nebraska - Lincoln. 
Published in Journal of Youth and Adolescence 40 (2011), pp. 568-581; doi: 10.1007/s10964-010-9551-4

Copyright $(2010$ Springer Science+Business Media, LLC. Used by permission.

Submitted February 22, 2010; accepted May 10, 2010; published online May 22, 2010.

A previous version of this paper was presented at the 2009 annual meeting of the Society for the Study of Social Problems in San Francisco, CA.

\title{
School-Based Extracurricular Activity Involvement and Adolescent Self-Esteem: A Growth-Curve Analysis
}

\author{
Lisa A. Kort-Butler and Kellie J. Hagewen \\ Department of Sociology, University of Nebraska-Lincoln, \\ 711 Oldfather Hall, P.O. Box 880324, Lincoln, NE 68588-0324, USA \\ Corresponding author - L. A. Kort-Butler, e-mail lkortbutler2@unl.edu
}

\begin{abstract}
Research on adolescent self-esteem indicates that adolescence is a time in which individuals experience important changes in their physical, cognitive, and social identities. Prior research suggests that there is a positive relationship between an adolescent's participation in structured extracurricular activities and well-being in a variety of domains, and some research indicates that these relationships may be dependent on the type of activities in which adolescents participate. Building on previous research, a growth-curve analysis was utilized to examine self-esteem trajectories from adolescence (age 14) to young adulthood (age 26). Using 3 waves of data from National Longitudinal Study of Adolescent Health ( $n=5,399 ; 47.8 \%$ male), the analysis estimated a hierarchical growth-curve model emphasizing the effects of age and type of school-based extracurricular activity portfolio, including sports and school clubs, on self-esteem. The results indicated that age had a linear relationship with self-esteem over time. Changes in both the initial level of self-esteem and the growth of self-esteem over time were significantly influenced by the type of extracurricular activity portfolio. The findings were consistent across race and sex. The results support the utility of examining the longitudinal impact of portfolio type on well-being outcomes.
\end{abstract}

Keywords: Self-esteem, Extracurricular activities, Adolescence, Growth-curves

In general, there appears to be a positive relationship between an adolescent's participation in structured extracurricular activities and well-being in a variety of domains (Busseri et al. 2006; Gilman et al. 2004). The skills and social networks built through extracurricular participation are thought to enhance school commitment and achievement, educational and occupational attainment, and promote well-being, healthy choices, and prosocial behavior (Eccles et al. 2003; Marsh and Kleitman 2002). Some research indicates that these relationships may in part be dependent on the type of activities in which adolescents participate (Bartko and Eccles 2003; Larson et al. 2006). The majority of adolescents report some level of school-based extracurricular involvement (Feldman and Matjasko 2005), making extracurricular activities a key arena for understanding the processes and outcomes of adolescent development.

Although researchers have taken longitudinal approaches to examine these relationships, there is less information regarding how extracurricular participation in high school impacts the trajectory of an adolescent's wellbeing into young adulthood. Furthermore, research has yet to establish how different types of participation may influence this trajectory. To address these issues, this article focuses on self-esteem as one outcome of school-based extracurricular involvement. Following the recommendation of Feldman and Matjasko (2007), it considers variation in adolescents' extracurricular portfolios, examining those who participate in only one type of school-based activity, those who participate in more than one type, and non-participants. In particular, using a growth curve model 
for self-esteem, the article explores how participation in sports and school clubs and how nonparticipation impact adolescents from mid-adolescence into young adulthood. Additionally, because of potential race and sex differences in both extracurricular participation and self-esteem, the article examines growth curves divided by race and sex.

\section{Self-Esteem and Extracurricular Involvement}

\section{Self-Esteem}

Self-esteem is a pivotal variable. A positive and resilient self-image, as opposed to negative or mutable selfesteem, is considered a crucial resource for resisting the negative implications for the self that are the frequent accompaniments of personal changes and other stressful experiences (Turner and Roszell 1994). Self-esteem buffers emotional consequences of stressors and significantly reduces psychological symptoms (Thoits 1995). Low self esteem is linked to problems such as life dissatisfaction, physical health problems, depression, substance abuse, suicidal behavior, and aggressive behavior (Crocker and Wolfe 2001; Trzesniewski et al. 2003). As such, low self-esteem represents a vulnerability factor that substantially increases the risk for negative outcomes (Turner and Lloyd 1999; Turner and Roszell 1994).

Research suggests that self-esteem destabilizes during adolescence, such that there is a drop in self-esteem in early adolescence and a recovery between midand late-adolescence (Baldwin and Hoffman 2002; Block and Robins 1993; Quatman and Watson 2001; Trzesniewski et al. 2003). This is attributed to pubertal changes, shifts in roles and responsibilities, shifts in personal identity as adolescents try to find somewhere to "fit in," as well as variation in support from family and friends (Greene and Way 2005; Quatman and Watson 2001; Trzesniewski et al. 2003). Self-concept, which refers to one's description of one-self and appraisals of competencies within various domains, is a critical element to one's overall evaluation of personal worth (Eccles et al. 1989; Findlay and Bowker 2009). For example, research conducted by Shapka and Keating (2005) noted that changes in various domains of self-competence, including physical, social, and scholastic domains, contributed to changes in general self-worth. As adolescents mature, their self-concept stabilizes and its various components become more integrated (Cole et al. 2001; Young and Mroczek 2003). By young adulthood, there is stabilization in physical and social change, which also contributes to the stabilization of self-esteem (Baldwin and Hoffman 2002).

\section{Extracurricular Activities and Self-Esteem}

The settings of extracurricular activities serve as one place to act out the developmental tasks of adolescence, at both the personal and interpersonal levels (Feldman and Matjasko 2005; Hansen et al. 2003). Involvement in extracurricular activities provides adolescents with a context for self-assessment outside the more restricted expectations of school and family settings (Barber et al. 2001). Such activities are theorized to provide adolescents with a place to establish their own identities on which to build self-esteem. Essentially, extracurricular activities are thought to give adolescents room to grow, by promoting and challenging self-esteem in the context of skill-building and emotional support (Darling 2005; Khanlou 2004). For instance, studies looking at sports involvement in particular find a beneficial relationship with self-esteem (Daniels and Leaper 2006; Erkut and Tracy 2002; Holland and Andre 1994; Tracy and Erkut 2002). In general, research suggests that extracurricular participation is linked to self-esteem (Broh 2002; Mahoney et al. 2006).

When more refined analyses are conducted, research also suggests that the observed benefits may depend partly on how activity participation is operationalized. For example, Snyder and Spreitzer (1992) characterized students' participation based on the researchers' objectively created role typology. They reported that "scholarathletes" and "pure scholars" had higher rates of self-esteem than those who were identified as "pure athletes" or neither. Fredricks and Eccles (2005) used both a dichotomous measure of participation in different activities and a measure of time spent in the activity per week. Based on the former measure, they found some differences in self-esteem between those who were involved in school clubs and those who were not. Based on the latter measure, they found that neither time spent in sports nor time spent in other organized activities predicted selfworth. Such studies suggest the importance of specifying activity type when researching extracurricular activity.

In light of this equivocal evidence, researchers have moved beyond examining extracurricular involvement in general to examining patterns of participation in different types of activities. According to this position, involvement in several types of activities provides more opportunity to experience those factors that promote successful development (Fredricks and Eccles 2006a, b). Further, the social and psychological advantages of participation may extend across activity domains (Marsh and Kleitman 2002). As a result of validation in one activity, a sense of self-pride or self-satisfaction can carryover to other domains (Todd and Kent 2003). This can potentially compensate for negative self-appraisals in some domains, bolstering self-esteem (Fredricks and Ec- 
cles 2006a, b). By implication, if an adolescent has fewer contexts in which to validate specific self-concepts, general self-esteem may be more vulnerable to negative appraisals. Research indicates that students involved across domains, such as involvement in sports, academics, and school clubs, have better psychological adjustment on measures like self-esteem and psychological resiliency, particularly compared to those students who do not participate (Fredricks and Eccles 2006a, b; Simpkins et al. 2008). In their sample tracing changes from eighth to eleventh grade, Fredricks and Eccles (2008) noted a time-lagged effect of sports and out-of- school activities on resiliency and self-esteem, which they argued represents the time it may take for an adolescent to build and gain support for a sense of self associated with these activities.

One way in which to examine participation across domains is to consider adolescents' activity portfolios or profiles (Bartko and Eccles 2003; Metzger et al. 2009; Peck et al. 2008). According to Feldman and Matjasko (2007), "activity portfolios describe the combinations of extracurricular activities in order to capture the complexity of participation during adolescence" (p. 315). For example, adolescents' self-reported participation can be categorized as sport-only involvement, activities-only involvement, mixed involvement, or involvement in neither. Research using this approach demonstrated that adolescents with mixed portfolios have the highest levels of self-esteem and those who are involved in neither have the lowest levels (Blomfield and Barber 2009; Harrison and Narayan 2003). When data allowed researchers to identify more types of portfolios, similar outcomes were discovered. Although Bartko and Eccles (2003) found no difference in self-esteem, they did find that highly involved adolescents had higher levels of psychological resiliency and lower levels of internalizing and externalizing problems. Similarly, Metzger et al. (2009) found that multiply-involved adolescents had lower levels of negative affect. These studies support the utility of using cluster or portfolio-based measures to describe extracurricular activity involvement.

\section{The Role of Race and Sex}

Research on the influence of the demographic characteristics of race/ethnicity and sex on extracurricular activity participation is equivocal. Pederson (2005) found no race differences in activity profiles. In contrast, Darling (2005) noted race/ethnicity differences. Whites were more likely to be involved than Blacks, and Hispanics had the lowest rates of involvement. Whites also had the highest levels of involvement across domains, with the exception of school clubs, where Blacks had greater participation. Examining sex differences in participa- tion, research indicates that boys are more likely than girls to participate in sports exclusively (Darling 2005; Eccles et al. 2003; Pederson 2005). Findings regarding other types of participation are mixed with some studies showing more variation than others. Research suggests that girls participate in more total activities and a wider range of activities, and girls are more likely to be involved in multiple activity types (Eccles et al. 2003; Feldman and Matjasko 2007).

If rates of participation do vary by race or sex, it may also be the case that the effects of participation may vary. For example, Crosnoe (2002) noted variation by sex in the relationship between athletic involvement and academic and substance use outcomes. Tracy and Erkut (2002) found variation by race and sex in the relationship between athletic involvement and self-esteem. Using measures of breadth, intensity, and duration of extracurricular involvement, Randall and Bohnert (2009) noted significant racial/ethnic differences in well-being. Although some race and sex differences in the relationship between extracurricular activity participation and well-being have been documented, several studies indicate no broad differences by race or sex (e.g., Marsh and Kleitman 2002; Simpkins et al. 2008). However, closer examination reveals some race and sex differences related to the type of activity and the outcome measured (Fredricks and Eccles 2006b, 2008). For instance, Gadbois and Bowker (2007) found that sports involvement was more relevant for boys' well-being, whereas non-athletic involvement was more relevant for girls. Findings like these have been attributed to variation in the nature and structure of extracurricular activities, as well as variation in peer group contexts within activities, which may carry different meanings for people of different social backgrounds (Fredricks and Eccles 2006b, 2008). Taken together, the nuances by race and sex that are revealed in the literature on extracurricular participation and wellbeing suggest that more research is warranted.

\section{The Current Study}

Although researchers have evaluated the complex relationship among extracurricular involvement and a host of adolescent outcomes, there is less information on how participation in school-based extracurricular activities impacts social psychological factors into young adulthood. If extracurricular involvement builds character, then those effects should extend to self-esteem in young adulthood. For example, studies conducted by Eccles and Barber (1999) and by Marsh and Kleitman (2002) involved samples that followed respondents from adolescence to young adulthood, examining risk behaviors, educational, and occupational outcomes. However, 
neither of these studies examined social psychological outcomes like self-esteem in young adulthood. Barber et al. (2001) did examine young adults' psychological outcomes and found involvement to be beneficial for selfesteem, but like other studies they did not take statistical approaches that allowed them to examine growth or decay over time by pattern of activity involvement. In addition, none of these studies examined potential race or sex differences in growth or decay by pattern of involvement.

Based on the review of the research, the current study tested the hypothesis that self-esteem would grow and stabilize from mid-adolescence (age 14) to young adulthood (age 26). A second hypothesis was that extracurricular activity participation had benefits for self-esteem over time, centering on two questions. Did extracurricular activity participation affect where an adolescent started in terms of self-esteem? How did it affect the change experienced with age? Based on the literature, those who participated in activities were expected to begin with higher levels of self-esteem than those who did not participate. Further, those who participated were expected to have more stable self-esteem throughout adolescence compared to those who did not participate.

Additional research questions centered on whether activity portfolios mattered for self-esteem trajectories. In other words, were there differences in self-esteem trajectories for those with different activity portfolios? The literature provides no consistent answer regarding differences in self-esteem trajectories among adolescents who participate in school-based sports, schoolbased non-athletic activities, a combination of activities, or who do not participate in any school-based activities. If activity portfolios differently affect adjustment, then an adolescent's portfolio may influence not only where self-esteem starts, but how it changes over time. Finally, the current study conducted analyses separated by race and by sex to explore if the impact of participation on self-esteem trajectories differed by these characteristics.

\section{Methods}

\section{Data and Participants}

To examine these hypotheses regarding activity participation and self-esteem trajectories, three waves of data from the National Longitudinal Study of Adolescent Health (Add Health) were utilized. Add Health is a nationally representative, probability-based survey of adolescents in grades seven through twelve at the first wave. The survey employed a stratified, random sample design of all high schools in the United States. High schools were stratified by region, urbanicity, school size and type, grade span, and percent White and Black. A sample of eighty high schools and fifty-two middle schools from the Northeastern, Midwestern, Southern, and Western regions of the United States were selected with an unequal probability of selection. The high schools became the cluster identifier, thus the primary sampling units for participants. All students in attendance on the day of administration were eligible to complete the in-school questionnaire. Then, sampling from their school roster, some students and their families were asked to participate in in-home interviews.

Interviewers began contacting adolescents from eligible schools and their families between 1994 and 1995 during the first wave of data collection (Harris et al. 2008). Respondents completed in-school questionnaires and then were interviewed at home by trained interviewers using Computer-Assisted Personal Interviews and Audio Computer-Assisted Self Interviews for sensitive questions. Wave 2 data collection via in-home interviews began in April 1996 and ended in August 1996, and followed the same mode of questioning as Wave 1. Data collection for Wave 3 began in July 2001 and concluded in April 2002 (Harris et al. 2008). As such, there is approximately a 1-2 year time-frame between Waves 1 and 2, and almost 5 or 6 years between Wave 2 and Wave 3.

The analysis was limited to those participants who were between the ages of fourteen and nineteen at Wave 1 (mean age at Wave $1=15.47$ ), who were enrolled in school during the initial year of data collection, and who completed all three waves of data collection. The sample lends itself to an accelerated longitudinal design because it consists of members of multiple birth cohorts (Raudenbush and Chan 1993). This design allows one to plot the development of self-esteem from mid-adolescence (age 14) to young adulthood (age 26). The final sample size consisted of 5,399 subjects, and 16,197 individual observations of self-esteem over the three waves.

\section{Measures}

\section{Self-Esteem}

Self-esteem was a time-varying covariate that was measured as the response to four questions at each of the three waves. The items parallel the Rosenberg (1989) global self-esteem scale and include: you have many good qualities; you have a lot to be proud of; you like yourself just the way you are; and you feel you are doing things just about right. Response categories coded from zero (strongly disagree) to four (strongly agree). The scale ranged from 0 to 16 , so that higher values indicated higher self-esteem. The alpha coefficient for the scale was 0.79 at Wave $1,0.80$ at Wave 2 and 0.79 at Wave 3. 


\section{School-Based Extracurricular Activity Involvement}

Extracurricular activity involvement was a time-constant covariant measured on baseline in-school questionnaire. At Wave 1, respondents were presented with a checklist of 33 school-based clubs, organizations, and sports teams and asked to mark all the activities that they "are participating in this year, or that you plan to participate in later in the school year." Students were also asked to indicate if they "did not participate in any clubs, organizations, or teams at school." We created four mutually exclusive participation categories using the Add Health list of activities. These categories included: (1) sports only portfolio, (2) clubs only portfolio, (3) mixed portfolio, and (4) non-participation. The individual activities that comprise these categories are listed in Table 1.

Students could select from a wide variety of clubs and activities; however, to maintain appropriate subsample sizes for the analysis, clubs were collapsed into one category. A respondent who responded "yes" to at least one sport and "no" to all clubs was categorized as having a sports only portfolio. A subject who responded "yes" to at least one club and "no" to all sports was categorized as having a clubs only portfolio. Those who responded "yes" to at least one sport and "yes" to at least one club were categorized as having a mixed portfo- lio. Those who responded "no" to all were categorized as having no participation in school-based extracurricular activities and used as the reference group in the analysis. Table 1 shows the distribution of respondents across groups. Unfortunately, participants were only asked about their extracurricular activity involvement during the first wave of data collection. A similar variable was not included in the second or third wave of the data, meaning that extracurricular activity involvement could only be examined as a time-constant covariate in this analysis.

\section{Demographic Variables}

Race was a dummy variable where White was the reference group, and the categories were Black, Hispanic, and other. Sex was a dummy variable, where female was the reference group. Analyses also controlled for the socioeconomic status of the household using a measure of highest level of education achieved by an adult in the household. The item was coded so that: $1=8$ th grade or less; $2=$ more than 8 th grade but did not graduate from high school; 3 = went to a business, trade, or vocational school instead of high school; $4=$ high school graduate or completed GED; 5 = went to a business, trade or vocational school after high school; $6=$ went to college but did not graduate; 7 = graduated from a col-

Table 1. School-based extracurricular activity portfolios and sample distribution across activities

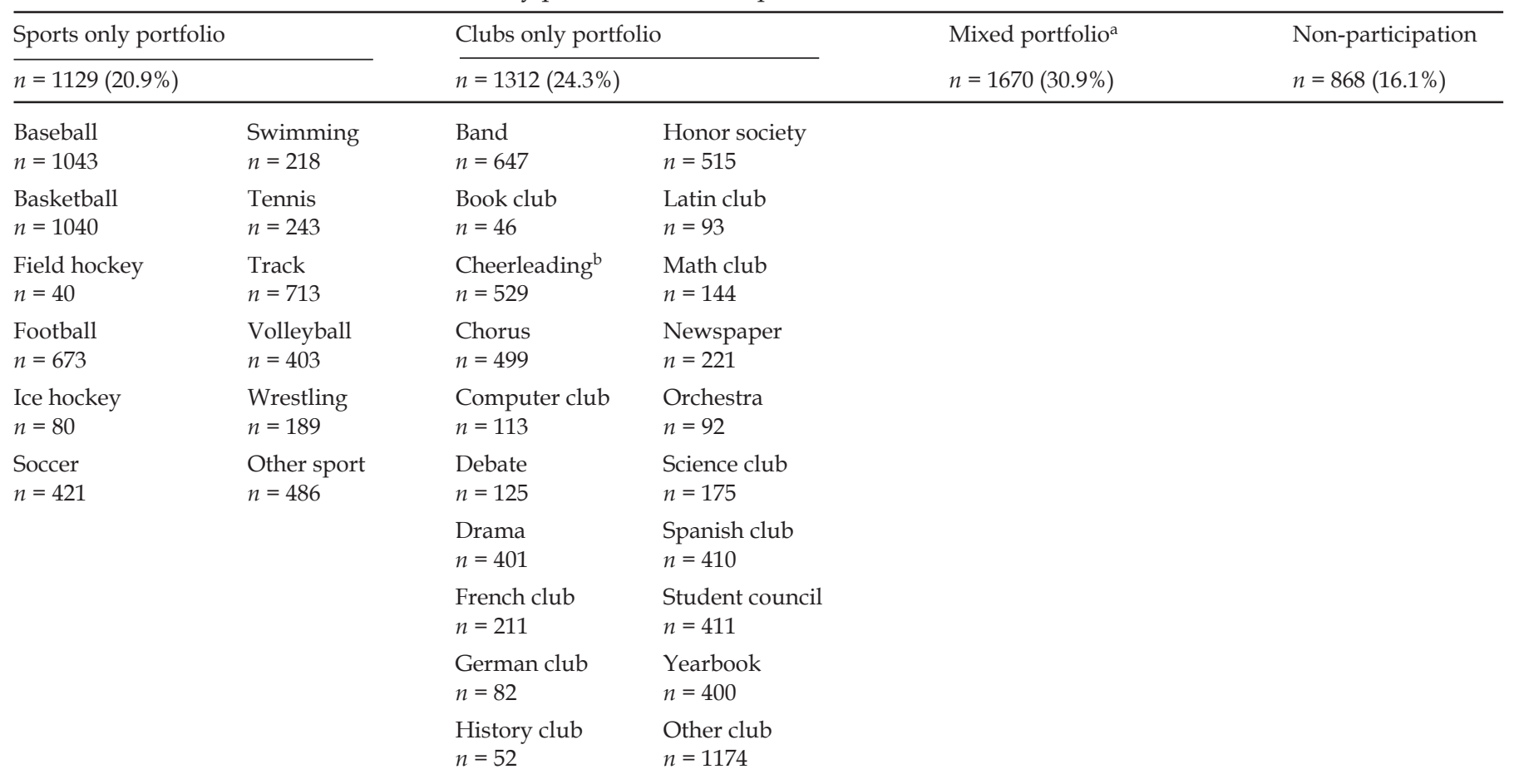

a. Includes respondents who participated in at least one sport and one club

b. Factor analysis indicated cheerleading was a better fit with the "clubs only" category as opposed to the "sports only" category 
lege or university; 8 = professional training beyond a 4-year college or university. In addition, a dummy variable was created for parent's report of current receipt of public assistance.

\section{Analysis Plan}

The PROC MIXED procedure from the SAS statistical package (Littell et al. 1996; Singer 1998) was used to estimate the effects of extracurricular activity involvement and sociodemographic predictors on initial mean levels of self-esteem and age-change trajectories of selfesteem over the period covered by the three waves of data. Multilevel models are ideal for investigating continuous outcomes like self-esteem whose values change systematically over time. At the first level are individual growth trajectories. In the simplest case of linear growth, each person's trajectory can be described with an intercept (starting point) and a slope (linear rate of change). At the second level are average trajectories, with individual and group deviations from the average. This allows for an examination of differences in intercept and slope. Similar to the approach used by Raudenbush and Chan (1993), in this study, individual "growth" in self-esteem was linked to the respondent's age and activity portfolio. The age variable was rescaled so that a zero value equaled age fourteen, thereby providing an interpretable intercept. Growth curve modeling provides estimates of both random effects (i.e., variation in individuals' means and slopes and deviation from own slope of self-esteem) and fixed effects (i.e., average effects of predictors on self-esteem across participants). As the current study focuses on whether initial mean-level differences or age-related changes are attributable to variations in activity portfolio or sociodemographic characteristics, only the fixed effects are reported here.

A graph of mean-level self-esteem across all ages indicated that age had a linear effect among respondents (see Figure 1). That is, average levels of self-esteem increased with age. Possible non-linear effects of age on self-esteem were tested by including age-squared and age-cubed terms in the model, but neither was statistically significant. Consequently, the age-squared and age-cubed terms were not included in the model as fixed effects.

\section{Results}

\section{Bivariate Relationships}

Table 2 displays the bivariate relationships between activity portfolio type and each of the variables considered

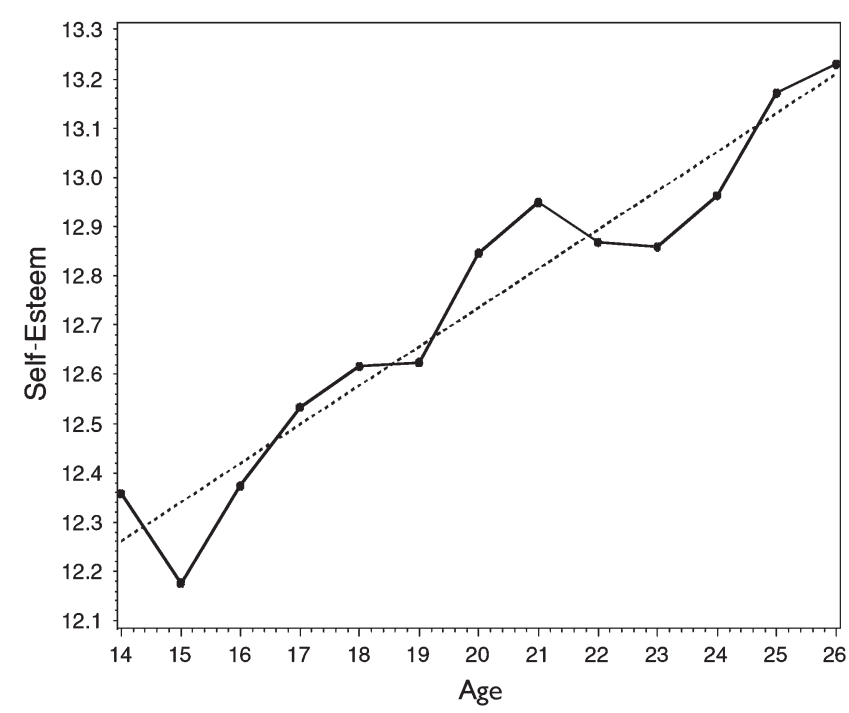

Figure 1. Changes in mean levels of self-esteem across age

in the multivariate analysis. The largest percentage of males $(32.9 \%)$ participated in sports only and the smallest percentage $(14.2 \%)$ participated in clubs only. Conversely, the largest percentage of females $(34.7 \%)$ had mixed portfolios and the smallest percentage $(9.9 \%)$ participated in sports only. There was less variation across racial/ethnic groups, as the largest percentage of Whites $(34.8 \%)$, Blacks $(29.5 \%)$, and other races $(32.4 \%)$ had mixed portfolios. The largest percentage of Hispanics $(25.2 \%)$, however, participated in clubs only. As for socioeconomic status, average parental education was the same for those participating in sports only, clubs only, and mixed activities (5.4), and is slightly lower for nonparticipants (4.7). The largest percentage of those receiving public assistance $(26.0 \%)$ participated in clubs only. Finally, those with mixed portfolios had the highest levels of self-esteem in each of the three waves of data $(12.6,12.9$, and 13.0, respectively).

\section{Growth Curve Analysis}

The basic model examined the fixed effects of linear age on self-esteem (e.g., Self-Esteem $=\alpha_{1}+\beta_{11 \text { linear age }}$ ). The main model examined the additional fixed effects of activity portfolio, race/ethnicity, sex, and socioeconomic status on "starting points" of self-esteem (e.g., Self-Esteem $=\alpha_{2}+b_{21 \text { linear age }}+\beta_{22 \text { sports only }}+\beta_{23 \text { clubs only }}+\beta_{24}$ mixed portfolio $+\beta_{25 \text { Black }}+\beta_{26 \text { Hispanic }}+\beta_{27 \text { other }}+\beta_{28 \text { male }}+\beta_{29}$

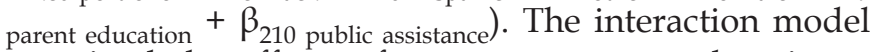
examined the effects of two-way cross-product interaction terms, formed by multiplicative combinations of age and activity portfolio, to determine differences across portfolio groups in the growth of self-esteem over time. 
Table 2. Bivariate relationships of study variables by extracurricular activity portfolio

\begin{tabular}{|c|c|c|c|c|}
\hline Study variables & $\begin{array}{l}\text { Sports only } \\
\text { portfolio }\end{array}$ & $\begin{array}{l}\text { Clubs only } \\
\text { portfolio }\end{array}$ & $\begin{array}{l}\text { Mixed } \\
\text { portfolio }\end{array}$ & Non-participation \\
\hline \multicolumn{5}{|l|}{ Gender } \\
\hline \%Male & 32.9 & 14.2 & 26.8 & 15.4 \\
\hline$\%$ Female & 9.9 & 33.6 & 34.7 & 16.7 \\
\hline \multicolumn{5}{|l|}{ Ethnicity } \\
\hline \%White & 21.3 & 23.7 & 34.8 & 14.4 \\
\hline \%Black & 22.2 & 24.8 & 29.5 & 14.2 \\
\hline \%Hispanic & 19.5 & 25.21 & 8.9 & 23.9 \\
\hline \%Other & 17.8 & 25.4 & 32.4 & 16.9 \\
\hline \multicolumn{5}{|l|}{ Socioeconomic status } \\
\hline Parent education (mean) & 5.4 & 5.4 & 5.4 & 4.7 \\
\hline$\%$ Public assistance & 17.7 & 26.0 & 21.7 & 23.6 \\
\hline \multicolumn{5}{|l|}{ Self-esteem } \\
\hline Wave I mean & 12.5 & 12.1 & 12.6 & 11.7 \\
\hline Wave II mean & 12.8 & 12.6 & 12.9 & 12.0 \\
\hline Wave III mean & 13.0 & 12.9 & 13.0 & 12.6 \\
\hline
\end{tabular}

The results of the growth-curve analyses are presented in Table 3. The basic model introduced the effects of age on self-esteem. As suggested by Figure 1, age had a significant linear effect $(\beta=.08, p<0.001)$ on self-esteem. Further, the large effect for the intercept $(\sigma$ $=11.05, p<0.001$ ) indicates that the initial levels of selfesteem were highly diverse among the sample. The results of the estimated random effects baseline model indicate that there was significant variability among the individual intercepts $\left(\tau_{00}=25.80, p<0.001\right)$ and individual slopes $\left(\tau_{11}=0.05, p<0.001\right)$, that there was significant covariance between the intercepts and slopes $\left(\tau_{10}\right.$ $=-1.12, p<0.001$ ), and that there remained significant variability at baseline after accounting for the effect of age $\left(\sigma^{2}=2.79, p<0.001\right)$.

The main model included the addition of fixed effects of activity portfolio type, race/ethnicity, sex, and socioeconomic status. Compared to non-participants, the initial mean level of self-esteem was significantly higher for those who participated in sports only $(\beta=0.36, p<$ $0.001)$, clubs only $(\beta=0.41, p<0.001)$ and mixed activities $(\beta=0.66, p<0.001)$. Additionally, initial mean levels of self-esteem were higher for Blacks compared to whites $(\beta=0.60, p<0.001)$, males compared to females $(\beta=0.56, p<0.001)$, and the initial mean level of selfesteem increased significantly with each unit increase in parental education $(\beta=0.04, p<0.01)$. On the other hand, the initial mean level of self-esteem was significantly lower for those of other races compared to Whites $(\beta=-0.41, p<0.001)$.

The interaction model included the interaction of each type of activity portfolio type by age on self-esteem.
The interaction between age and the sports only portfolio $(\beta=-0.07, p<0.001)$ and the interaction between age and the mixed portfolio $(\beta=-0.07, p<0.001)$ attained statistical significance, indicating that age trends in selfesteem for these groups differed from non-participants. As seen in Figure 2, the significant negative interactions indicate that the self-esteem trajectories for the sports only portfolio and the mixed portfolio increased at a significantly less steep rate than the self-esteem trajectories of non-participants. The interaction term was not significant for the clubs only portfolio, indicating that that trajectory was not significantly different from non-participants. Figure 2 also reveals a trend towards convergence across portfolio type. By young adulthood, people had similar levels of self-esteem, with an indication that those with a clubs-only portfolio may surpass the other groups.

\section{Results for Analysis by Race/Ethnicity}

Additional models were run to test whether the relationship between activity portfolio type and self-esteem varied by race/ethnicity. This was accomplished by including interactions between each of the racial/ethnic categories (Black, Hispanic, and other, with White as the reference group) and age, interactions between each of the racial/ethnic categories and activity portfolio, and three-way interactions between each of the racial/ethnic categories, activity portfolio, and age. The results of these models are presented in Table 4 . The two-way interactions between racial/ethnic category and activity portfolio tested whether portfolio type had 
Table 3. Predictors of self-esteem and self-esteem trajectories from mid-adolescence (age 14) to young adulthood (age 26)

\begin{tabular}{|c|c|c|c|c|c|c|}
\hline \multirow[t]{2}{*}{ Variable } & \multicolumn{2}{|c|}{ Basic model } & \multicolumn{2}{|c|}{ Main model } & \multicolumn{2}{|c|}{ Interaction model } \\
\hline & $\bar{\beta}$ & SE & $\bar{\beta}$ & SE & $\beta$ & SE \\
\hline Intercept & $11.05^{\star * *}$ & 0.11 & $10.09^{* * *}$ & 0.14 & $9.37 * * *$ & 0.23 \\
\hline Age & $0.08^{* * *}$ & 0.01 & $0.08^{* * *}$ & 0.01 & $0.12^{* * *}$ & 0.01 \\
\hline \multicolumn{7}{|l|}{ Activity portfolio } \\
\hline Sports only & & & $0.36^{* * *}$ & 0.08 & $1.68^{* * *}$ & 0.32 \\
\hline Clubs only & & & $0.41^{* * *}$ & 0.07 & $0.66^{*}$ & 0.31 \\
\hline Mixed portfolio & & & $0.66^{* * *}$ & 0.05 & $1.91^{* * *}$ & 0.29 \\
\hline \multicolumn{7}{|l|}{ Race/ethnicity } \\
\hline Black & & & $0.60^{* * *}$ & 0.06 & $0.60^{* * *}$ & 0.06 \\
\hline Hispanic & & & 0.03 & 0.07 & 0.03 & 0.07 \\
\hline Other & & & $-0.41^{* * *}$ & 0.09 & $-0.41^{* * *}$ & 0.09 \\
\hline \multicolumn{7}{|l|}{ Sex } \\
\hline Male & & & $0.56^{* * *}$ & 0.05 & $0.57^{* * *}$ & 0.05 \\
\hline \multicolumn{7}{|l|}{ Socioeconomic status } \\
\hline Parent education & & & $0.04^{* *}$ & 0.01 & $0.04^{* *}$ & 0.01 \\
\hline Public assistance & & & 0.07 & 0.10 & 0.07 & 0.10 \\
\hline \multicolumn{7}{|l|}{ Interactions } \\
\hline Sports only by age & & & & & $-0.07^{* * *}$ & 0.02 \\
\hline Clubs only by age & & & & & -0.01 & 0.02 \\
\hline Mixed portfolio by age & & & & & $-0.07^{* * *}$ & 0.01 \\
\hline
\end{tabular}

All parameter entries are maximum-likelihood estimates using SAS PROC MIXED.

Non-participants are the reference group for activity portfolios. White is the reference group for race/ethnicity.

${ }^{*} p<.05 ;{ }^{* *} p<.01 ; * * * \quad<.001$

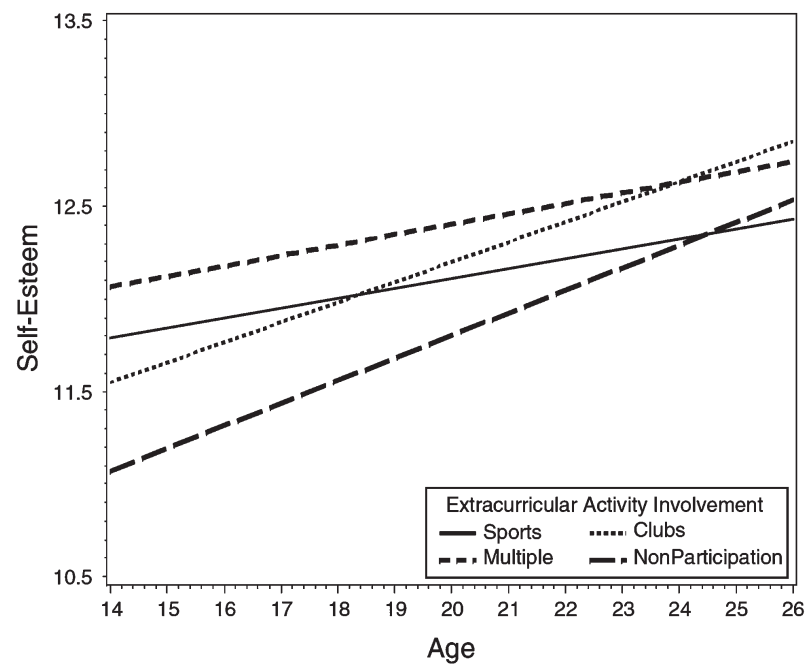

Figure 2. Trajectories of self-esteem by age and extracurricular activity portfolio

a significantly different relationship with initial mean levels of self-esteem for the different racial/ethnic categories. None of these interactions attained statistical significance, indicating that the effects of activity portfolio operated similarly for each racial/ethnic group considered. The two-way interactions between racial/ ethnic category and age tested whether or not the tra- jectory of self-esteem was the same for each racial/ethnic category considered. Again, none of these interactions attained statistical significance, indicating that the self-esteem trajectories for each racial/ethnic category increased at similar rates. Finally, the three-way interaction between each of the racial/ethnic categories, activity portfolio, and age tested if the relationship between activity portfolio and self-esteem trajectory operated the same for each racial/ethnic category considered. These interactions were not significant, indicating no difference across racial/ethnic groups in the influence of portfolio type on self-esteem trajectories.

\section{Results for Analysis by Sex}

The analyses also tested whether the relationship between activity portfolio type and self-esteem varied by sex. This was accomplished by including interactions between sex (male $=1$ ) and age, interactions between sex and activity portfolio type, and three-way interactions between sex, activity portfolio, and age. The results of these models are presented in Table 5. The two-way interactions between sex and activity portfolio tested whether portfolio type had a significantly different 
Table 4. Predictors of self-esteem and self-esteem trajectories: analysis by race/ethnicity

\begin{tabular}{|c|c|c|c|c|}
\hline \multirow[t]{2}{*}{ Effect } & \multicolumn{2}{|c|}{$\begin{array}{l}\text { 2-Way interaction } \\
\text { model }\end{array}$} & \multicolumn{2}{|c|}{$\begin{array}{l}\text { 3-Way interaction } \\
\text { model }\end{array}$} \\
\hline & $\beta$ & SE & $\beta$ & SE \\
\hline \multicolumn{5}{|l|}{ Sports only by } \\
\hline Black & -0.16 & 0.19 & -0.52 & 0.81 \\
\hline Hispanic & 0.10 & 0.20 & 0.35 & 0.87 \\
\hline Other & -0.01 & 0.28 & -1.34 & 1.21 \\
\hline \multicolumn{5}{|l|}{ Clubs only by } \\
\hline Black & 0.05 & 0.19 & -1.11 & 0.79 \\
\hline Hispanic & 0.10 & 0.19 & -0.85 & 0.82 \\
\hline Other & 0.31 & 0.26 & 0.22 & 1.11 \\
\hline \multicolumn{5}{|l|}{ Mixed portfolio by } \\
\hline Black & -0.04 & 0.18 & -0.97 & 0.75 \\
\hline Hispanic & 0.09 & 0.20 & 0.92 & 0.85 \\
\hline Other & 0.33 & 0.24 & -0.23 & 1.05 \\
\hline \multicolumn{5}{|l|}{ Age by } \\
\hline Sports only & $-0.07^{* * *}$ & 0.02 & $-0.07^{* *}$ & 0.02 \\
\hline Clubs only & -0.01 & 0.02 & -0.03 & 0.02 \\
\hline Mixed portfolio & $-0.06^{* * *}$ & 0.01 & $-0.07^{* * *}$ & 0.02 \\
\hline Black & -0.02 & 0.01 & -0.05 & 0.03 \\
\hline Hispanic & 0.01 & 0.02 & 0.01 & 0.03 \\
\hline Other & 0.01 & 0.02 & -0.01 & 0.04 \\
\hline \multicolumn{5}{|c|}{ Sports only by age by } \\
\hline Black & & & 0.02 & 0.04 \\
\hline Hispanic & & & -0.01 & 0.04 \\
\hline Other & & & 0.07 & 0.04 \\
\hline \multicolumn{5}{|c|}{ Clubs only by age by } \\
\hline Black & & & 0.06 & 0.06 \\
\hline Hispanic & & & 0.05 & 0.04 \\
\hline Other & & & 0.00 & 0.06 \\
\hline \multicolumn{5}{|c|}{ Mixed portfolio by age by } \\
\hline Black & & & 0.05 & 0.04 \\
\hline Hispanic & & & -0.04 & 0.04 \\
\hline Other & & & 0.03 & 0.05 \\
\hline
\end{tabular}

All parameter entries are maximum-likelihood estimates using SAS PROC MIXED. Direct effects of age, activity portfolios, race/ ethnicity, sex, and socioeconomic status are included in the model (not shown). Non-participants are the reference group for activity portfolios. White is the reference group for race/ethnicity.

${ }^{*} p<.05 ;{ }^{* *} p<.01 ;{ }^{* * *} p<.001$

relationship with initial mean levels of self-esteem for males compared to females. These interactions did not attain statistical significance, indicating that activity portfolio operated the same for males and females. The two-way interactions between sex and age tested whether or not the trajectory of self-esteem was the same for males and females. The interaction between sex and age was significant $(\beta=-0.09, p<0.001)$ indicating that age trends in self-esteem differed for males and females, such that self-esteem trajectories were significantly less steep for males than for females. These results are consistent with previous studies indicating that male and female self-esteem develops differently during adolescence (Kling et al. 1999). Finally, the three-way interaction between sex, activity portfolio type, and age tested if the relationship between activity portfolio and self-esteem trajectories operated the same for males and females. The interactions tested were not significant, indicating the relationship between activity portfolio and self-esteem trajectories did not significantly vary by sex.

\section{Discussion}

Adolescence is a time in which individuals experience key changes in their physical, cognitive, and social identities, which they carry into young adulthood. Involvement in extracurricular activities is thought to contribute to these developmental processes by providing important skills, building social networks, and shaping self-concepts. Indeed, research suggests that there is a positive relationship between an adolescent's participation in structured extracurricular activities and wellbeing in a variety of domains. Furthermore, research suggests that these relationships may, in part, be dependent on the types of activities in which adolescents participate. By exploring the trajectory of self-esteem from mid-adolescence (age 14) to young adulthood (age 26) as a function of activity portfolios, the study reported here adds to this body of literature.

Overall, results demonstrated growth in self-esteem from mid-adolescence into young adulthood regardless of activity portfolio. Those who participated in schoolbased extracurricular activities had higher initial levels of self-esteem compared to those who did not participate. Consistent with other research, those with mixed portfolios had the highest initial levels of self-esteem. Interestingly, over time, those who did not participate in any school-based activity and those who had a clubs only portfolio experienced the most growth in self-esteem. Those with a sports only portfolio and those with a mixed portfolio experienced some growth in self-esteem, but this was less dramatic than the other two groups. By young adulthood, people had comparable levels of self-esteem, and there was some indication that those who were only involved in clubs may surpass those who were involved in sports alone. Consistent with other research, results demonstrated no statistically significant variation by either race or sex. In this study, the relationship between school-based extracurricular activity participation and self-esteem trajectories were comparable for Whites and non-whites and for males and females. 
Table 5. Predictors of self-esteem and self-esteem trajectories: analysis by sex

\begin{tabular}{|c|c|c|c|c|}
\hline \multirow[t]{2}{*}{ Effect } & \multicolumn{2}{|c|}{ 2-Way interaction model } & \multicolumn{2}{|c|}{ 3-Way interaction model } \\
\hline & $\beta$ & SE & $\beta$ & SE \\
\hline Sports only by male & 0.24 & 0.16 & 0.73 & 0.69 \\
\hline Mixed Portfolio by male & 0.10 & 0.14 & 0.39 & 0.58 \\
\hline Age by sports only & $-0.05^{\star *}$ & 0.02 & -0.03 & 0.03 \\
\hline Age by male & $-0.09 * * *$ & 0.01 & $-0.08^{* * *}$ & 0.02 \\
\hline Sports only by age by male & & & -0.03 & 0.03 \\
\hline Clubs only by age by male & & & 0.01 & 0.03 \\
\hline Mixed portfolio by age by male & & & -0.02 & 0.03 \\
\hline
\end{tabular}

All parameter entries are maximum-likelihood estimates using SAS PROC MIXED. Direct effects of age, activity portfolios, race/ ethnicity, sex, and socioeconomic status are included in the model (not shown). Non-participants are the reference group for activity portfolios.

${ }^{*} p<.05 ;{ }^{* *} p<.01 ;{ }^{* * *} p<.001$

Although portfolio type mattered for initial levels of self-esteem, it did not appear to contribute to long-term differences across groups. Cole et al. (2001) provide one explanation for these results. Their research found that self-concept related to sports and academics stabilized during mid- to late-adolescence. This suggests that by mid- to late-adolescence, both participants and non-participants may have constructed identities based on the social roles they occupy, and that participation or nonparticipation, whatever they entail, reinforces those identities, closing the gap in self-esteem.

Why might clubs-only involvement matter more over time? Previous research suggests that a loss of sportscentered identity may have negative consequences. For example, Snyder and Spreitzer's (1992) research found that those who left the scholar-athlete role usually moved to a pure scholar role, while those who left the athlete role moved to the non-scholar/non-athlete role, a role associated with the poorest outcomes. Similarly, Harter and White (2003) proposed that college freshmen who experience a decline in self-esteem may be in a situation where a once valued status, like "star athlete," is less relevant. On the other hand, those who experience an increase in self-esteem may find a situation in which a once-devalued status, like "computer geek," is more relevant. Students whose self-esteem remained stable may be involved in several activities that translated to similar domains of activities in young adulthood, so that they found continued support for domain-specific self-concepts and general self-esteem.

Thus, adolescents who are involved in a mix of extracurricular activities have more to fall back on as they transition to young adulthood, particularly if they lose their status as "athlete." In the study reported here, change in portfolio composition could not be measured. However, as the sample aged, it could be the case that those who were involved in athletics had fewer opportunities to participate in organized sports activities that were associated with the same level of prestige (e.g., high school athletes may not go to compete at a collegiate level). As a result, they may have experienced a loss of that status and any benefits associated with it, particularly if they were not involved in other kinds of roles or activities. However, students who participated in clubs may have been in a better position to maintain their involvement and may have found the associated skill-set to still be personally relevant and socially valued, which benefited their selfesteem. In sum, adolescents who have clubs as part of their portfolio or who have a club only portfoliothe two groups with the highest levels of self-esteem by young adulthood in this study - may benefit more in the long run because the associated self-concepts and skill-sets are more readily transferable to young adulthood.

Why do non-participants show the most growth? In part, this finding can be attributed to the normative developmental pattern of self-esteem shown in this study and described in previous research. These adolescents also started with lower self-esteem, so they had a larger potential for growth relative to the other groups. In part, this finding may be an artifact of the data, in that some of the students in this category may not have been truly "non-participants." Students reported participation at one point in time, so they may not have remained nonparticipants as time progressed. It may also be the case that some of the adolescents in this group may have engaged in activities not captured by the data, such as community organizations. These data limitations are discussed below. 


\section{Limitations and Future Directions}

Although the Add Health data provide a consistent measure of self-esteem across three waves of data, several data limitations surrounded the measurement of extracurricular participation. First, the item measures either current participation or plans to participate at some point in the school year. Certainly, an adolescent's plans may change for a variety of reasons, including deciding not to participate, not being selected to participate, being ineligible, or having time or resource restrictions. An adolescent may also decide later to participate in an activity he or she had not initially planned to join. However, research using a college sample suggested that plans to engage in an activity were highly correlated to actual participation a year later (Ajzen and Driver 1992) providing some evidence that intention maps onto participation.

Another limitation was that the measure includes only school-based activities as part of an adolescent's portfolio. Adolescents can spend their free time in a variety of ways not captured by measuring participation in school-based extracurricular activities (Darling 2005; Fredricks and Eccles 2008; Shanahan and Flaherty 2001). For example, Larson et al. (2006) reported significant developmental benefits for adolescents who participated in faith-based activities and community service organizations. Future research should consider how involvement in such activities in comparison to school-based activities impacts social psychological outcomes over time.

This study was also limited by the inability to measure activity participation over time. Add Health only inquired about specific extracurricular involvement in Wave One. There is evidence for continuity in participation over time (Feldman and Matjasko 2005), although there may be a tendency for students to narrow their focus with age (Côté 1999; Findlay et al. 2009). For example, research suggests that high school adolescents with high levels of extracurricular participation tend to remain high in participation; those with low levels tend to decrease participation or participate with less consistency over time (Busseri et al. 2006; Pederson 2005; Rose-Krasnor et al. 2006; Shanahan and Flaherty 2001). Despite these trends, Denault and Poulin (2009) reported that initial levels of participation were better predictors of later outcomes than were rates of change. Such research lends reliability to the measure of participation used here. Nonetheless, fluctuations in participation could affect self-esteem trajectories. Future research should consider patterns of involvement over time and how pattern shifts impact trajectories of self-esteem and other outcomes.

Two other issues temper the results. First, to simplify analyses, responses were restricted to only four portfolio types. Previous research has identified mul- tiple portfolio types (e.g., Peck et al. 2008), and future research should consider a broader range of portfolios. Second, as with other research on extracurricular activity, there is concern linked to potential selection effects. Other researchers have commented on how adolescents may self-select for activities, as well as how structural barriers within a given school or community may constrain availability and options (Darling 2005; Feldman and Matjasko 2005; Guest and Schneider 2003; Marsh and Kleitman 2002). Unfortunately, although the current study specifically analyzed or controlled for some demographic characteristics that may be associated with participation, the analysis was unable to control for all potential selection variables.

In light of these limitations, this study should be considered a conservative, exploratory test of the relationship between school-based extracurricular activity involvement and self-esteem trajectories from mid-adolescence to young adulthood. Future research should address two key issues. First, in addition to examining a broader range of portfolios, research examining trajectories of self-esteem and other measures of well-being should consider greater specification by sport and activity. For example, school-based sports can be teamoriented like football or more individually-oriented like golf. Similarly, schools may have performing arts activities that are open to anyone in the school population, as well as choirs or bands that require audition or invitation. As noted above, adolescents may also be involved in a wide-range of activities not related to school, such as religious and service organizations, intramural sports leagues, and community performing arts groups. Presumably, while some socialization experiences may be similar across domains, there is clearly room for variation in how different activities contribute to identity development, skill-building, and other social and psychological factors (Feldman and Matjasko 2007; Fredricks and Eccles 2008).

Second, previous research demonstrates intriguing relationships between activity participation and other mental health outcomes (Guest and McRee 2009). For example, Fredricks and Eccles (2005) noted that time spent in sports and time spent in school clubs protected students against depression, an effect mediated by peer relationships. On the other hand, Hoffman (2006) found that athletes had higher levels of substance use, as did Eccles and Barber (1999). The current study supports the utility of examining the longitudinal impact of portfolio type on well-being outcomes. Inconsistencies may be resolved using statistical approaches, like that used in this analysis, that examine growth or decay in outcomes like depression, substance use, and other conduct problems. Examining change in these outcomes over time as a function of activity portfolio may add to our under- 
standing of the benefits or limitations of extracurricular participation during adolescence and into adulthood.

This research supports the role school-based extracurricular involvement plays in the development of adolescents into young adulthood. Such activities provide adolescents a place to establish their own identities and develop important skills on which to build self-esteem. However, the benefits to self-esteem are linked to adolescents' activity portfolios. In particular, participation in school-based clubs as a teen contributed to the growth and stability of self-esteem into young adulthood. This relationship held regardless of race/ethnicity or sex, supporting the idea that school-based extracurricular participation can be beneficial regardless of social background. In sum, young adults do benefit from participating in school-based extracurricular activities during adolescence, provided that the activities in which they participate are associated with self-concepts and skill-sets that remain relevant beyond high school.

Acknowledgments - This article uses data from Add Health, a program project designed by J. Richard Udry, Peter S. Bearman, and Kathleen Mullan Harris, and funded by a grant P01HD31921 from the Eunice Kennedy Shriver National Institute of Child Health and Human Development, with cooperative funding from 17 other agencies. Special acknowledgment is due Ronald R. Rindfuss and Barbara Entwisle for assistance in the original design. Persons interested in obtaining data files from Add Health should contact Add Health, Carolina Population Center, 123 W. Franklin Street, Chapel Hill, NC 275162524 (addhealth@unc.edu). The authors also thank three anonymous reviewers for Journal of Youth and Adolescence for their insightful comments and constructive critiques.

\section{References}

Ajzen, I., \& Driver, B. L. (1992). Application of the theory of planned behavior to leisure choice. Journal of Leisure Research, 24, 207-224.

Baldwin, S. A., \& Hoffman, J. P. (2002). The dynamics of self-esteem: A growth-curve analysis. Journal of Youth and Adolescence, 31, 101-113.

Barber, B. L., Eccles, J. S., \& Stone, M. R. (2001). Whatever happened to the jock, the brain, and the princess? Young adult pathways linked to adolescent activity involvement and social identity. Journal of Adolescent Research, 16, 429-455.

Bartko, W. T., \& Eccles, J. S. (2003). Adolescent participation in structured and unstructured activities: A person-oriented analysis. Journal of Youth and Adolescence, 32, 233-241.

Block, J., \& Robins, R. W. (1993). A longitudinal study of consistency and change in self-esteem from early adolescence to early adulthood. Child Development, 64, 909-923.

Blomfield, C. J., \& Barber, B. L. (2009). Brief report: Performing on the stage, the field, or both? Australian adolescent extracurricular activity participation and self-concept. Journal of Adolescence, 32, 733-739.
Broh, B. A. (2002). Extracurricular programming to academic achievement: Who benefits and why? Sociology of Education, 75, 69-95.

Busseri, M. A., Rose-Krasnor, L., Willoughby, T., \& Chalmers, H. (2006). A longitudinal examination of breadth and intensity of youth activity involvement and successful development. Developmental Psychology, 42, 1313-1326.

Cole, D. A., Maxwell, S. E., Martin, J. M., Peeke, L. G., Seroczynski, A. D., Tram, J. M., et al. (2001). The development of multiple domains of child and adolescent self-concept: A cohort sequential longitudinal design. Child Development, 72, 1723-1746.

Côté, J. (1999). The influence of the family in the development of talent in sport. The Sport Psychologist, 13, 395-417. Crocker, J., \& Wolfe, C. T. (2001). Contingencies of self-worth. Psychological Review, 108, 593-623.

Crosnoe, R. (2002). Academic and health-related trajectories in adolescence: The intersection of gender and athletics. Journal of Health and Social Behavior, 43, 317-335.

Daniels, E., \& Leaper, C. (2006). A longitudinal investigation of sport participation, peer acceptance, and self-esteem among adolescent girls and boys. Sex Roles, 55, 875-880.

Darling, N. (2005). Participation in extracurricular activities and adolescent adjustment: Cross-sectional and longitudinal findings. Journal of Youth and Adolescence, 34, 493-505.

Denault, A., \& Poulin, F. (2009). Intensity and breadth of participation in organized activities during the adolescent years: Multiple associations with youth outcomes. Journal of Youth and Adolescence, 38, 1199-1213.

Eccles, J. S., \& Barber, B. L. (1999). Student council, volunteering, basketball, or marching band: What kind of extracurricular involvement matters? Journal of Adolescent Research, 14, 10-43.

Eccles, J. S., Barber, B. L., Stone, M., \& Hunt, J. (2003). Extracurricular activities and adolescent development. Journal of Social Issues, 59, 865-889.

Eccles, J. S., Wigfield, A., Flanagan, C. A., Miller, C., Reuman, D. A., \& Yee, D. (1989). Self-concepts, domain values, and selfesteem: Relations and changes at early adolescence. Journal of Personality, 57, 283-310.

Erkut, S., \& Tracy, A. J. (2002). Predicting adolescent self-esteem from participation in school sports among Latino subgroups. Hispanic Journal of Behavioral Sciences, 24, 409-429.

Feldman, A. F., \& Matjasko, J. L. (2005). The role of school-based extracurricular activities in adolescent development: A comprehensive review and future directions. Review of Educational Research, 75, 159-210.

Feldman, A. F., \& Matjasko, J. L. (2007). Profiles and portfolios of adolescent school-based extracurricular activity participation. Journal of Adolescence, 30, 313-332.

Findlay, L. C., \& Bowker, A. (2009). The link between competitive sport participation and self-concept in early adolescence: A consideration of gender and sport orientation. Journal of Youth and Adolescence, 38, 29-40.

Findlay, L. C., Garner, R. E., \& Kohen, D. E. (2009). Canadian children's organized physical activity: Patterns of participation. Journal of Physical Activity and Health, 6, 708-715.

Fredricks, J. A., \& Eccles, J. S. (2005). Developmental benefits of extracurricular involvement: Do peer characteristics medi- 
ate the link between activities and youth outcomes? Journal of Youth and Adolescence, 34, 507-520.

Fredricks, J. A., \& Eccles, J. S. (2006a). Extracurricular involvement and adolescent adjustment: Impact of duration, number of activities, and breadth of participation. Applied Developmental Science, 10, 132-146.

Fredricks, J. A., \& Eccles, J. S. (2006b). Is extracurricular participation associated with beneficial outcomes? Concurrent and longitudinal relations. Developmental Psychology, 42, 698-713.

Fredricks, J. A., \& Eccles, J. S. (2008). Participation in extracurricular activities in the middle school years: Are there developmental benefits for African American and European American youth? Journal of Youth and Adolescence, 37, 1029-1043.

Gadbois, S., \& Bowker, A. (2007). Gender differences in the relationships between extracurricular activities participation, selfdescription, and domain-specific and general self-esteem. Sex Roles, 56, 675-689.

Gilman, R., Myers, J., \& Perez, L. (2004). Structured extracurricular activities among adolescents: Findings and implications for school psychologists. Psychology in the Schools, 41, 31-41.

Greene, M. L., \& Way, N. (2005). Self-esteem trajectories among ethnic minority adolescents: A growth curve analysis of the patterns and predictors of change. Journal of Research on Adolescence, 15, 151-178.

Guest, A. M., \& McRee, N. (2009). A school-level analysis of adolescent extracurricular activity, delinquency, and depression: The importance of situational context. Journal of Youth and Adolescence, 38, 51-62.

Guest, A., \& Schneider, B. (2003). Adolescents' extracurricular participation in context: The mediating effects of schools, communities, and identity. Sociology of Education, 76, 89-109.

Hansen, D. M., Larson, R. W., \& Dworkin, J. B. (2003). What adolescents learn in organized youth activities: A survey of self-reported developmental experiences. Journal of Research on Adolescence, 13, 25-55.

Harris, K. M, Halpern, C. T., Entzel, P., Tabor, J., Bearman, P. S., \& Udry, J. R. (2008). The National Longitudinal Study of Adolescent Health: Research design. Accessed November 25, 2008, at http://www.cpc.unc.edu/projects/addhealth/design

Harrison, P. A., \& Narayan, G. (2003). Differences in behavior, psychological factors, and environmental factors associated with participation in school sports and other activities in adolescence. Journal of School Health, 73, 113-120.

Harter, S., \& White, N. R. (2003). Beyond the debate: Why some adolescents report stable self-worth over time and situation, whereas others report changes in self-worth. Journal of Personality, 71, 1027-1058.

Hoffman, J. P. (2006). Extracurricular activities, athletic participation, and adolescent alcohol use: Gender-differentiated and school-contextual effects. Journal of Health and Social Behavior, 47, 275-290.

Holland, A., \& Andre, T. (1994). Athletic participation and the social status of adolescent males and females. Youth and Society, 25, 388-407.

Khanlou, N. (2004). Influences on adolescent self-esteem in multicultural Canadian secondary schools. Public Health Nursing, 21, 404-411.
Kling, K. C., Hyde, J. S., Showers, C. J., \& Buswell, B. N. (1999). Gender differences in self-esteem: A meta-analysis. Psychological Bulletin, 123, 470-500.

Larson, R. W., Hansen, D. M., \& Moneta, G. (2006). Differing profiles of developmental experiences across types of organized youth activities. Developmental Psychology, 42, 849-863.

Littell, R. C., Miliken, G. A., Stroup, W. W., \& Wolfinger, R. D. (1996). SAS system for fixed models. Cary, NC: SAS Institute.

Mahoney, J. L., Harris, A. L., \& Eccles, J. S. (2006). Organized activity participation, positive youth development, and the overscheduling hypothesis. Social Policy Report, 20, 1-31.

Marsh, H. W., \& Kleitman, S. (2002). Extracurricular school activities: The good, the bad, and the nonlinear. Harvard Educational Review, 72, 464-514.

Metzger, A., Crean, H. F., \& Forbes-Jones, E. L. (2009). Patterns of organized activity participation in urban, early adolescents. Journal of Early Adolescence, 29, 426-442.

Peck, S. C., Roeser, R. W., Zarrett, N.,\& Eccles, J. S. (2008). Exploring the roles of extracurricular activity quantity and quality in the educational resilience of vulnerable adolescents: Variableand pattern-centered approaches. Journal of Social Issues, 64, 135-155.

Pederson, S. (2005). Urban adolescents' out-of-school activity profiles: Associations with youth, family, and school transition characteristics. Applied Developmental Science, 9, 107-124.

Quatman, T., \& Watson, C. M. (2001). Gender differences in adolescent self-esteem: An exploration of domains. The Journal of Genetic Psychology, 162, 93-117.

Randall, E. T., \& Bohnert, A. M. (2009). Organized activity involvement, depressive symptoms, and social adjustment in adolescents: Ethnicity and socioeconomic status as moderators. Journal of Youth and Adolescence, 38, 1187-1198.

Raudenbush, S. W., \& Chan, W. (1993). Application of a hierarchical linear model to the study of adolescent deviance in an overlapping cohort design. Journal of Consulting and Clinical Psychology, 61, 941-951.

Rose-Krasnor, L., Busseri, M. A., Willoughby, T., \& Chalmers, H. (2006). Breadth and intensity of youth activity involvement as contexts for positive development. Journal of Youth and Adolescence, 35, 385-499.

Rosenberg, M. (1989). Society and the adolescent self-image. Middletown, CT: Wesleyan University Press.

Shanahan, M. J., \& Flaherty, B. P. (2001). Dynamic patterns of time use in adolescence. Child Development, 72, 385-401.

Shapka, J. D., \& Keating, D. P. (2005). Structure and changed in self-concept during adolescence. Canadian Journal of Behavioural Science, 37, 83-96.

Simpkins, S. D., Eccles, J. S., \& Becnel, J. N. (2008). The mediational role of adolescents' friends in relations between activity breadth and adjustment. Developmental Psychology, 44, 1081-1094.

Singer, J. D. (1998). Using SAS PROC MIXED to fit multilevel models, hierarchical models, and individual growth models. Journal of Educational and Behavioral Statistics, 23, 323-355.

Snyder, E. E., \& Spreitzer, E. (1992). Social psychological concomitants of adolescents' role identities as scholars and athletes: A longitudinal analysis. Youth and Society, 23, 507-522. 
Thoits, P. A. (1995). Stress, coping, and social support processes: Where are we? What next? [Special issue]. Journal of Health and Social Behavior, 53-79.

Todd, S. Y., \& Kent, A. (2003). Student athletes' perceptions of self. Adolescence, 38, 659-667.

Tracy, A. J., \& Erkut, S. (2002). Gender and race patterns in the pathways from sports participation to self-esteem. Sociological Perspectives, 45, 445-466.

Trzesniewski, K. H., Donnellan, M. B., \& Robins, R. W. (2003). Stability of self-esteem across the life span. Journal of Personality and Social Psychology, 84, 205-220.

Turner, R. J., \& Lloyd, D. A. (1999). The stress process and the social distribution of depression. Journal of Health and Social Behavior, 40, 374-404.

Turner, R. J., \& Roszell, P. (1994). Psychosocial resources and the stress process. In W. R. Avison \& I. H. Gotlib (Eds.), Stress and mental health: Contemporary issues and prospects for the future (pp. 179-210). New York: Plenum Press.

Young, J. F., \& Mroczek, D. K. (2003). Predicting intraindividual self-concept trajectories during adolescence. Journal of Adolescence, $26,586-600$.

\section{The Authors}

Lisa A. Kort-Butler is an assistant professor of sociology at the University of Nebraska-Lincoln. She received a Ph.D. in sociology from North Carolina State University. Her current research examines adolescent well-being, particularly delinquency and depression, focusing on variations in stress and social/personal resources. She is also interested in media portrayals of crime and justice.

Kellie J. Hagewen is an assistant professor of sociology at the University of Nebraska-Lincoln. She received a Ph.D. in sociology from Duke University. Her research interests include disparities in physical and mental health behaviors, care, and outcomes over the life course, and marriage and fertility behavior over the life course. 